\title{
Maltese Radiographers' Attitudes towards Continuing Professional Development: An Initial Study Using Concept Maps
}

\author{
Joseph Castillo, $\mathrm{MSc}^{\text {a* }}$ and Carmel J. Caruana, $\mathrm{PhD}^{\mathrm{b}}$ \\ ${ }^{a}$ Medical Imaging Department, Mater Dei Hospital, Malta \\ ${ }^{\mathrm{b}}$ Biomedical Physics, Faculty of Health Sciences, University of Malta, Malta
}

\begin{abstract}
Purpose: The Council for the Professions Complementary to Medicine in Malta recently published a draft document regarding the introduction of mandatory continuing professional development (CPD) for radiographers. This study explored the attitudes and motivators of Maltese radiographers prior to the implementation of mandatory $\mathrm{CPD}$ in order to provide the necessary information required by management to develop CPD successfully. Concept maps are used as part of a methodology to analyse qualitative data.
\end{abstract}

Methods: All radiographers working in the National Health Service were invited to complete an anonymous web-based questionnaire.

Results: The study showed that participants generally had a positive attitude towards CPD but were concerned about the mandatory aspect. The participants were mostly motivated by increasing professional knowledge, updating existing qualifications, and enhancing the status of the profession as a whole. Radiographers identified several difficulties with respect to CPD participation, such as lack of funding, lack of management support, and not enough local CPD opportunities. CPD participation was also negatively influenced by family commitments.

Conclusion: The study showed that the majority of radiographers were self-motivated to engage in CPD activities, but there were some concerns. Based on these results, the authors suggest recommendations for allaying apprehension and producing the necessary conditions for a successful mandatory CPD scheme.

\section{Introduction}

Continuing professional development (CPD) provides a vehicle for professionals to maintain and develop their knowledge, skills, and competences (KSC) [1], where

\footnotetext{
The author declares no conflict of interest.

* Corresponding author: Joseph Castillo, Medical Imaging Department, Mater Dei Hospital, San Gwann, Malta.

E-mail address: joseph.castillo@gov.mt (J. Castillo).
}

\section{RÉSUMÉ}

Objet: Le Council of Professions Complimentary to Medicine (CPCM) de la République de Malte a publié récemment une ébauche sur la mise en place de la formation professionnelle continue (FPC) obligatoire pour les technologues en radiologie. L'étude examine les réactions et les motivations des technologues en radiologie du pays avant l'implantation de la FPC obligatoire pour recueillir les données nécessaires à la direction qui souhaite instaurer une FPC obligatoire réussie. On a utilisé les cartes conceptuelles dans la méthodologie d'analyse des données qualitatives.

Méthode: Tous les technologues en radiologie des services de santé nationaux ont été invités à répondre sans s'identifier à un questionnaire affiché sur le Web.

Résultats: L'étude a démontré que les participants se montraient plutôt positifs à l'égard de la FPC, mais qu'ils s'inquiétaient qu'on la rende obligatoire. Ils étaient avant tout motivés par l'augmentation des connaissances professionnelles, la mise à niveau des compétences et la hausse générale du niveau de la profession. Parmi les difficultés citées par les technologues en radiologie au sujet de la participation à la FPC, citons le manque de fonds, le manque d'appui de la direction, le manque de formations régionales. La participation à la FPC est aussi rendue difficile par les obligations familiales.

Conclusion: L'étude a démontré que la majorité des technologues en radiologie étaient motivés à participer à des activités de FPC, mais que certaines inquiétudes étaient présentes. À partir des résultats obtenus, les auteurs ont formulé des recommandations pour dissiper l'appréhension et produire les conditions nécessaires à une FPC obligatoire réussie.

"competences" includes the attributes of responsibility and autonomy in work and study situations as defined in the European Qualification Framework [2]. This implies that practitioners should assume responsibility in an autonomous manner for their professional practice and also for their own learning $[3,4]$. A CPD program should be developed by individuals or groups of professionals through a learning needs self-assessment and implemented along the continuum of lifelong learning [5]. CPD signifies a process of continuous 
improvement, initiated at the entry level to the profession and leading to an expert level in order to better serve society [6] and to improve their employability [7]. Health care professionals' autonomy and engagement in setting their own learning agenda is what differentiates CPD from continuous education [8], where learning outcomes and educational activities are planned by others. Although the autonomous participation in CPD has a voluntary aspect that may be interpreted by some health professionals as a personal decision to participate in or not, health professional councils lay down standards of practice in which members are to "embrace continuing education for optimal patient care, public education and enhanced knowledge and technical competence" [9]. The delivery of health care is concerned with quality and accountability. As health care organizations strive to develop their service portfolios, employees with direct customer contact must be endowed with the necessary competences to interact with their clients and technology. Often a new service fails because personnel have not been properly trained to sell and deliver the service [10].

In 2005, the United Kingdom became the first European country to introduce mandatory $\mathrm{CPD}$ participation as a prerequisite for radiographers to maintain registration. A preceding voluntary program that had been running for a number of years provided the Health Professions Council and the Society of Radiographers-United Kingdom with enough data to identify those resources that were necessary for a successful mandatory CPD process. Subsequently, the Health Professions Council set up a unique CPD framework based on standards to be achieved through a mixture of learning activities relevant to current and future practice, personal contribution to practice and service development, and assessed through a written portfolio of evidence. In addition, acknowledging that there are several approaches to CPD, the Health Professions Council determined that the portfolio of evidence should not be based on a specific number of credits or hours but the creation of a portfolio of reflective writing $[11,12]$.

On a Europe-wide level, the published literature on CPD within radiography is scarce and a comprehensive survey of the literature only identified one publication of note [13]. This study showed that the majority of European radiographers were in favor of CPD and introduced the possibility of a common Europe-wide CPD passport for radiography practitioners. Such a passport could be linked to a detailed European competence profile referenced directly to the European Qualification Framework. However, this study focussed only on the requirements necessary for the implementation of CPD in Europe, and the authors did not investigate the attitudes and motivators of European radiographers vis-à-vis mandatory $\mathrm{CPD}$ as a health policy for the maintenance of national registration. A study comparing UK radiographers with those in New Zealand indicated an ambivalent attitude to the implementation of mandatory CPD among UK radiographers [14].

In late 2010, the Council for the Professions Complementary to Medicine (CPCM) in Malta published a draft document proposing mandatory $\mathrm{CPD}$ for radiographers and other health care professionals. In this draft, the CPCM recommended that radiographers be required to acquire a minimum of $45 \mathrm{CPD}$ credits over a period of 3 years. These credits were to be selected from an approved list of activities from different categories, which included publication, self-directed learning, attendance at organized educational programs, and other professional activities (Society of Medical Radiographers-Malta, personal communication; email to J. Castillo, December 2010).

The great majority of radiographers in Malta work in the National Health Service (NHS), which includes two general hospitals, one oncology hospital, and four small health centres equipped with $\mathrm{x}$-ray units. These radiologic services carry out 210,000 investigations per year and are coordinated through the medical imaging department located in the greater of the two general hospitals. Although this department does not have its own official CPD unit to monitor the KSC and learning needs of radiographers, evidence from the Society of Medical Radiographers-Malta and the Malta Magnetic Resonance Radiographers Group websites suggests that Maltese radiographers do participate in the CPD activities organized by these organizations. With the introduction of mandatory CPD, Maltese radiographers will be faced with the responsibility of identifying their learning needs and of planning their own professional development in a more structured way.

The aim of this study was to assess the situation regarding CPD attendance, attitudes and motivators among Maltese radiographers with respect to mandatory CPD prior to its implementation. The study would provide the Medical Imaging Department management with information to create communities of practice that would act as incubators for the development of staff expertise to a level consonant with the service quality targets of the organization $[15,16]$.

\section{Methodology}

The project was deemed to be a staff survey, and permission to conduct the study was sought from the Clinical Chair for Medical Imaging Services in Malta. The Manager for Medical Imaging Services was informed of the research project. A covering letter accompanied the questionnaire and assured participants that all responses would be treated with confidentiality and anonymity.

\section{Design}

A survey research strategy was adopted using a web-based questionnaire to collect data. This electronic collection of data was important to guarantee anonymity and confidentially; this was particularly important so as to avoid response bias as the author holds a managerial position within the Medical Imaging Department. The survey began in December 2010 and was completed in January 2011.

A published questionnaire used in a similar study for nurses [5] was modified to be directed to radiographers. The 
questionnaire consisted of sections addressing demographic data, occupational data, participation in and attitudes to CPD activities, and intrinsic/extrinsic motivators influencing participants' willingness to participate in CPD. The latter consisted of a list of 14 motivational statements to which a 5-point Likert-type scale was attached (ranging from "strongly disagree" to "strongly agree"). Respondents had to indicate whether each of the factors influenced their degree of participation in CPD. Participants were also queried regarding their awareness of the process of lifelong learning (LLL) and its relationship to CPD.

\section{Sample}

All 124 radiographers employed in all grades within the Maltese NHS were sent an email explaining the purpose of the study and providing them with a link to the web-based questionnaire. Radiographers with a temporary working status were excluded as their expectations may have differed with regards to $\mathrm{CPD}$.

\section{Data Analysis}

Quantitative data were analysed using the statistical features provided by Excel 2007. A Cronbach's alpha coefficient test established internal consistency $(\alpha=0.93)$ for the motivator statements. Qualitative data from open-ended questions were analysed using concept maps. Concept maps have been used as a strategy to deal with the methodological challenges of qualitative research [17]. A concept map can be used to frame a research project, reduce qualitative data, analyse themes and interconnections in a study, and present findings [18]. "A concept map is a schematic device for representing a set of concept meanings embedded in a framework of propositions" ([19], p15). Concept maps are created with the broader, more inclusive concepts at the top of the hierarchy, connecting through linking words with other concepts that can be subsumed. Concept maps are an important strategy in qualitative inquiry because they help the researcher focus on meaning. The maps allow the researcher to see participants' meaning as well as the connections that participants discuss across concepts or bodies of knowledge. Additionally, the maps support researchers in their attempts to make sure that qualitative data are embedded in a particular context.

Concept maps also can be used as a strategy to search out and analyse themes in qualitative research [20]. To identify these overarching themes, the researcher has to identify interconnections between concepts. If the researcher is searching for specific interconnections, a concept map can be created from the transcripts that demonstrate these connections. For example, in one study on how professionals learn, the researcher was looking for the connections participants made between what they learned in formal continuing education programs and their professional practice [21]. Concept maps can also be used to help create a category or coding scheme in qualitative research. After the maps are created from each interview or observation, the researcher can go through them looking for levels of hierarchy, interconnections, and repeated concepts. These items then may indicate emerging themes [18].

The major disadvantage of using concept maps in qualitative work seems to be their complexity. The maps can be difficult to read for participants unfamiliar with the format, and the linkages may be harder to see as the maps get more and more complex. Additionally, the complexity at times makes it difficult for the reader to determine which concepts are of critical importance and which are of secondary importance. Because of this complexity, it is most often necessary to use other data analysis strategies in conjunction with the maps.

Concept maps in this study were used to reduce the qualitative data so as to facilitate the process of understanding key ideas (see Figure 1). They were also used as an efficient way of presenting findings. The concept maps provided an insight into the radiographers' perceptions of CPD and lifelong learning and whether they have developed the necessary values and attitudes required to promote this development.

\section{Results}

A total of 71 complete responses were returned, giving a response rate of $57 \%$.

\section{Demographic Profile}

The data reveal a young radiography community, where $53 \%$ are between 20 and 29 years old and 29\% between 30 and 39 years. As regards gender, the sample in the study was fairly balanced between males (45\%) and females (55\%).

The majority of the group are single (including divorced, separated, widowed) (63\%), whereas $37 \%$ are married (including living with a partner). Participants having children comprised $30 \%$. In addition, $69 \%$ of the respondents had followed an undergraduate degree program in radiography leading to professional registration. A modest group of radiographers $(21 \%)$ had also followed postgraduate courses.

\section{Occupational Profile}

Radiographers in Malta work on a triple shift system (morning 07:30 AM-2:30 PM, afternoon 2:30 PM-7:30 PM, night 7:30 PM-07:30 AM of the following day). Half of the participants $(50 \%)$ work morning shift only, while the rest rotate between shifts. Cross-tabulating by gender and type of shift indicated that $62 \%$ of the men work on the rotating shift system and $71 \%$ of the women work on a morning shift-only basis.

Furthermore, $66 \%$ and $32 \%$ of the respondents work in hospitals and local health centres, respectively. A small number of radiographers (18\%) also do part-time work in private health settings.

\section{CPD Participation}

It was found that $63 \%$ of the respondents had participated in some form of CPD during the previous year (2010). Cross tabulating participation in CPD and working on a rotating shift basis or working morning shifts only indicates that those 


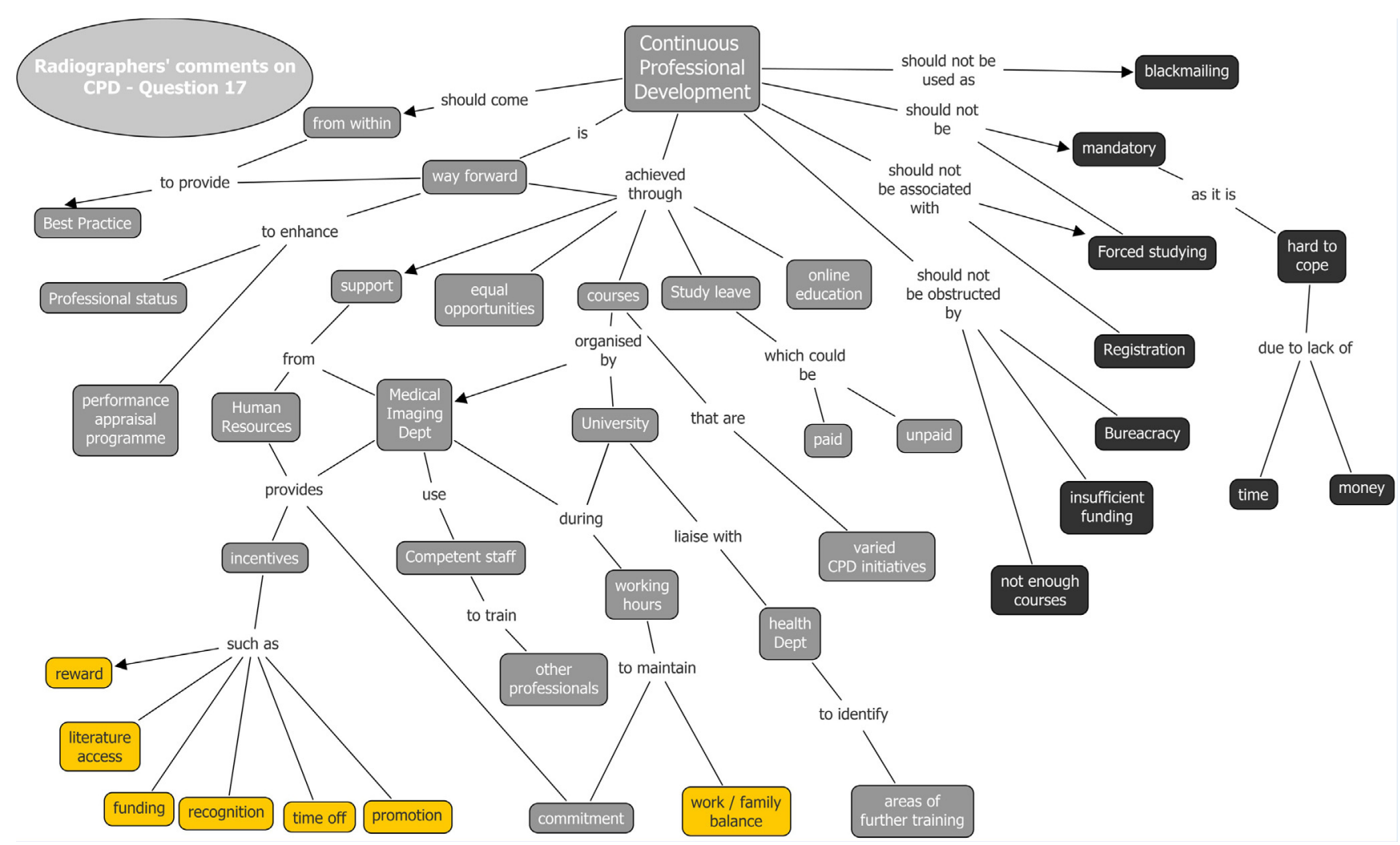

Figure 1. Concept map: Radiographers' perception of continuing professional development.

who work on a rotating shift engaged less $(29 \%)$ in CPD activity than those who work mornings only (68\%).

Cross tabulating CPD participation against marital status (Table 1) and having children (Table 2) indicated that CPD participation was not unduly negatively influenced by marital status but was negatively influenced by family commitments.

Respondents who attended CPD activities were also asked to state the type of event. The majority participated in local CPD activities organized by the Society of Radiographers of Malta, the Malta Magnetic Resonance Radiographers Group, the Faculty of Health Sciences of the University of Malta, the national Centre for Development Research and Training [22], and the Malta Institute of Medical Education (Table 3). Only nine had attended conferences abroad.

Radiographers were queried with regard to the amount of free time they were willing to spend on CPD and whether they have enough CPD opportunities. The group was closely split between those who are willing to spend 1 to 5 hours a month (49\%) and those who were ready to spend between

Table 1

Participation in Continuing Professional Development Activities against Marital Status

\begin{tabular}{llll}
\hline $\begin{array}{l}\text { Participation } \\
\text { in CPD }\end{array}$ & $\begin{array}{l}\text { Single (Including Divorced, } \\
\text { Separated, or Widowed) }\end{array}$ & $\begin{array}{l}\text { Married/Living } \\
\text { with Partner }\end{array}$ & Totals \\
\hline Yes & 26 & 19 & $45(63 \%)$ \\
No & 14 & 12 & $26(37 \%)$ \\
\hline
\end{tabular}

6 and 10 hours a month (40\%). Further, $11 \%$ were undecided. The majority of radiographers (79\%) did not feel that there were enough CPD activities.

\section{Motivational Factors}

The responses on the Likert-type scale attached to the motivational statements (Table 4) were scored in order to obtain mean values in the following manner: $1=$ strongly disagree, $2=$ disagree, $3=$ uncertain, $4=$ agree, $5=$ strongly agree. Increasing professional knowledge, to update my existing qualifications, and to increase the status of the profession as a whole were rated as providing most motivation. To achieve a higher educational qualification because of a previous unsatisfactory education and completing a CPD course without study leave were rated as the least motivational factors.

\section{The Meaning of Lifelong Learning and CPD}

Participants were asked for their interpretation of both CPD and LLL to determine whether the motivational factors

Table 2

Participation in CPD Activities against Presence of Children

\begin{tabular}{llll}
\hline Participation in CPD & Children & No Children & Totals \\
\hline Yes & 11 & 33 & $44(62 \%)$ \\
No & 10 & 17 & $27(38 \%)$ \\
\hline
\end{tabular}

CPD, continuing professional development. 
Table 3

Frequency of Attendance at CPD Events

\begin{tabular}{llc}
\hline CPD Activity & Event Organizer & Responses \\
\hline Conference abroad & Various & 9 \\
MRI in practice course [23] & MMRRG & 18 \\
IV therapy & FHS & 8 \\
Forensic lecture & FHS & 4 \\
Local academic onference & SMR-M & 7 \\
MSc/postgraduate courses & FHS & 5 \\
Management & CDRT & 3 \\
Basic life support & FHS & 2 \\
Ultrasound (eFAST) & FHS & 8 \\
Others & Various & 8 \\
\hline
\end{tabular}

CDRT, Centre for Development Research and Training; CPD, continuing professional development; eFAST, extended focused assessment with sonography for trauma; FHS, Faculty of Health Sciences; IV, intravenous; MMRG, Malta Magnetic Resonance Radiographers Group; SMR-M, Society of Medical Radiographers-Malta.

were relevant to the concepts of LLL and CPD. Concepts maps were used to collate all the responses into one map. Colour was used to highlight the major concepts. With regard to LLL, the radiographers' responses could be categorized according to three overarching themes: continuous learning on a personal level to improve self-development, updating of skills and knowledge to improve professional status, and daily experiential learning through formal and informal learning (Figure 2).

Radiographers' responses to the question "what do you understand by the term CPD" were categorized on five emerging themes. It was described as a management tool effectively used to share information and implement changes. It was referred to as specific subject learning related to one's profession that is either organized formally at university or informally by the medical imaging department. It was also seen as a requirement by profession and society to ensure that members update their knowledge and introduce innovations. CPD was also viewed as an academic infrastructure, part of lifelong learning related to improving professional knowledge, skills, and competences (Figure 3).

\section{Discussion}

\section{Response Rate}

It is accepted that questionnaires in the behavioural sciences generally have a response rate of approximately $56 \%$ [24]. In a population where each participant has a workrelated email account, as in the case of Maltese radiographers employed in the NHS, a web survey application can achieve a comparable response rate to that of a surface mail questionnaire [25]. This study obtained a 57\% response rate, which is considered an adequate response.

\section{Constraints to CPD Participation}

In a similar study investigating radiographers' attitude to CPD before the implementation of mandatory CPD in the United Kingdom and New Zealand, a general ambivalent attitude towards CPD was reported. The causes included barriers such as lack of career structures, inadequate funding or salary, lack of time for CPD during office hours, remoteness, staff shortages, and busy workloads [14]. These barriers were common to other studies involving other health care professionals $[26,27]$.

This study reports similar findings and foresees that releasing a number of radiographers for CPD activities could be a logistical challenge for managers especially if the opportunities for CPD activities available throughout the year are not increased. The constraints such as lack of time and support experienced by radiographers who have participated in CPD have been highlighted through a number of comments.

I agree with CPD, however if it is compulsory then management should provide with an infrastructure which assists radiographers in achieving $\mathrm{CPD}$ - that is time during working hours in order to undertake CPD activities. Imaging teams have to adapt to this reality whilst management and HR have to support this good cause. More opportunities for everyone in varied CPD activities is also important. $\mathrm{CPD}$ can also be part of a performance appraisal programme for radiographers.

Table 4

Mean and Mode Values for Motivational Factors

\begin{tabular}{|c|c|c|c|}
\hline Answer Options & Rating Average & Mode & Response Count \\
\hline To fulfill statutory requirements to maintain registration. & 3.35 & 4 & 68 \\
\hline I will take up a CPD course if partially funded by my employer. & 3.90 & 4 & 67 \\
\hline I am prepared to pay for my CPD courses. & 2.88 & 3 & 67 \\
\hline I am willing to complete a course for my CPD without study leave. & 2.51 & 2 & 68 \\
\hline I am willing to complete a course for my CPD with partial study leave. & 3.44 & 4 & 66 \\
\hline To obtain a further qualification in order to apply for promotion. & 3.78 & 4 & 67 \\
\hline To update my existing qualifications. & 4.31 & 5 & 68 \\
\hline To achieve a higher educational qualification due to previous unsatisfactory education. & 2.74 & 2 & 68 \\
\hline I want to demonstrate that I am professionally competent. & 3.98 & 4 & 66 \\
\hline To increase my professional knowledge. & 4.61 & 5 & 69 \\
\hline To increase my self-esteem. & 3.54 & 4 & 67 \\
\hline To prevent myself from becoming bored. & 2.96 & 4 & 67 \\
\hline To increase the status of the practitioner. & 3.87 & 4 & 68 \\
\hline To increase the status of the profession as a whole. & 4.18 & 5 & 68 \\
\hline
\end{tabular}

CPD, continuing professional development. 


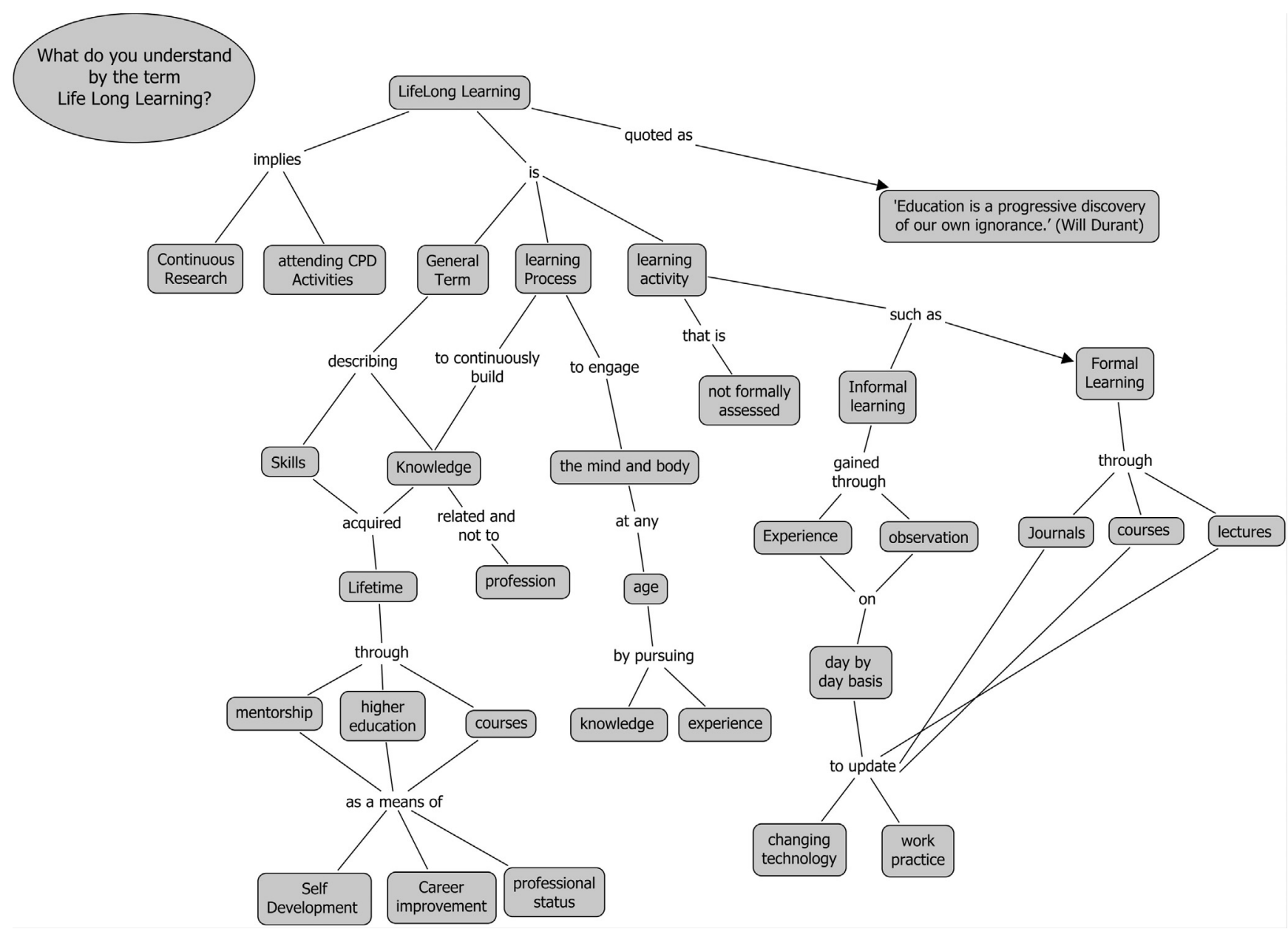

Figure 2. Concept map of radiographers' understanding of lifelong learning.

Our department should organise CPD courses as in other health professions and motivate the Radiographers to attend these courses through incentives. The department should allow time for its personnel to attend. Another good incentive could be better access to literature.

There definitely should be support for each professional, equally-both financially and with arrangements from management in order to allow/help workers carry out their further education. I believe that it is in management's own interest to provide means for their employees to carry out CPD.

Although CPD, whether mandatory or voluntary, is seen as a fundamental professional responsibility of the individual as laid down by the code of practice, these comments indicate that radiographers would like to see management share the responsibility and commitment for CPD. As funding remains one of the major obstacles blocking access to and motivation towards CPD, employers should cultivate a learning environment for CPD - and in so doing, accept partial responsibility for the financial outlay [28]. However, it is not just management that needs to have its role in CPD defined. The registration body, the professional society, and the Faculty of Health Science of the University of Malta all have roles to play in
CPD. This shared responsibility could be achieved by setting up a dedicated CPD unit with the remit of ensuring that the learning needs of Maltese radiographers and their professional development plans as agreed by employers and as provided by educators are congruent with the requirements of the CPCM and the professional bodies [29]. Since the majority of radiographers in Malta are located within one hospital, a community of practice or a learning organization approach would be the way forward for meeting the expectations of both patients and radiographers. The community of practice would require a manager with leadership skills who works with individuals to foster a collegial culture that values change and looks at failures as an opportunity to learn and improve [30].

Radiographers who were employed on a shift basis working morning, afternoon, and night duties participated less than those who worked morning duties only. Lack of time was highlighted in the comments above as the major reason to participate less in CPD; however, this could also have happened because CPD activities are not planned to cater for those who work on shift. Repeating CPD lectures over different time periods would make it possible for all radiographers within the NHS to attend. Another possible avenue is online learning. In contrast to the study by Palarm et al 


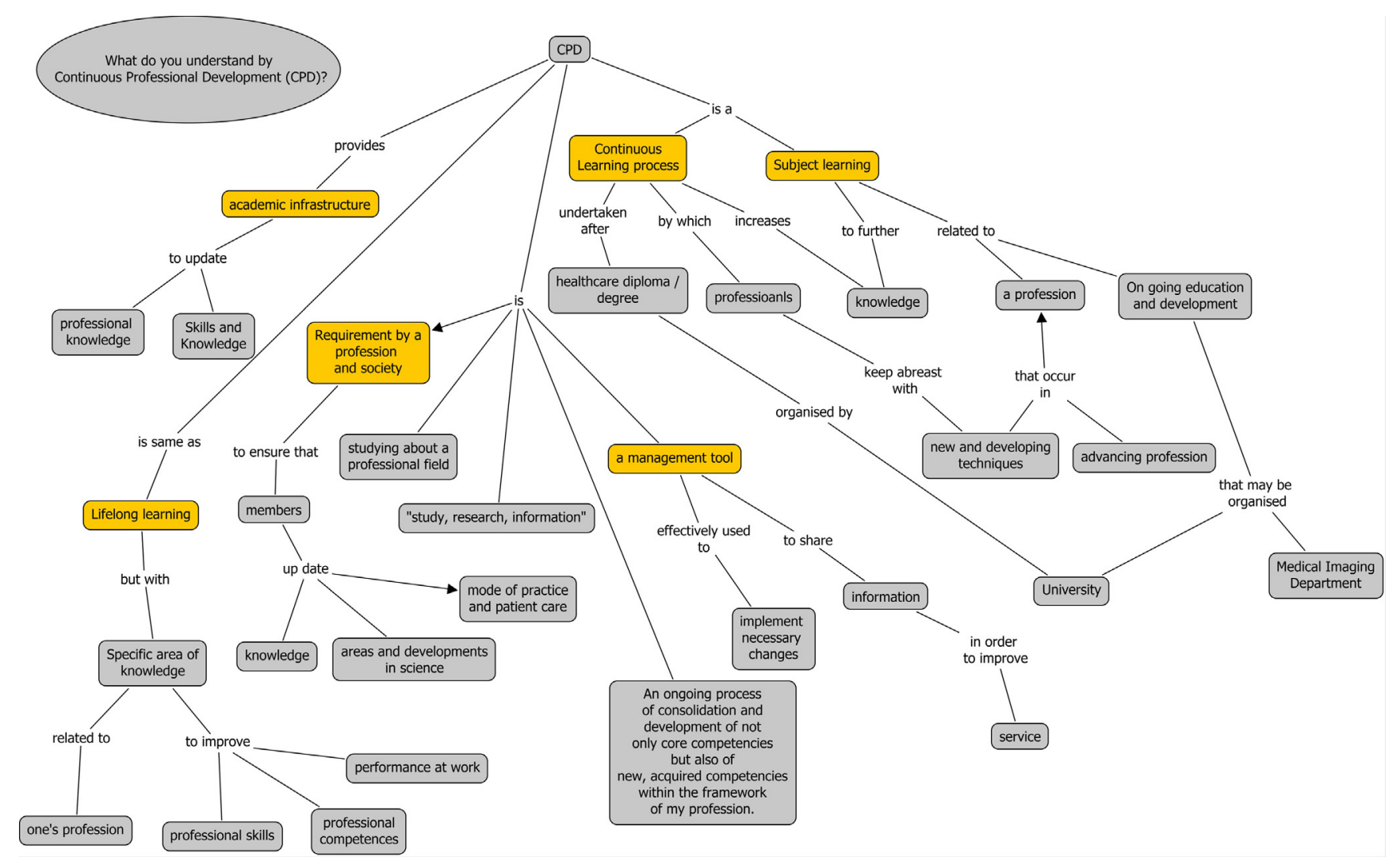

Figure 3. Concept map: Radiographers' understanding of continuing professional development.

[31], all workers working on rotating shifts in this study participated in CPD activities, indicating that flexible working hours may lead to a significant increase in CPD participation.

The majority of the radiographers (75\%) were of the opinion that the spectrum of available CPD activities specific to radiography was quite narrow. However, radiographers may also be imposing restrictions on themselves as informal learning was not mentioned by any of the participants as an opportunity of learning activity for CPD. This misconception, that $\mathrm{CPD}$ is simply attending an event or a formal course [32], needs to be addressed as there are numerous activities that can be done by an individual without incurring any expenses except for some protected time by management. Participation in multidisciplinary meetings, journal clubs, or serving on professional committees are examples of informal learning activities [33]. This is probably because the majority of radiographers do not have reflective thinking and writing skills, the courses for which were only introduced recently in undergraduate radiography programs [34]. Therefore, it may be easier to develop a portfolio with a list of certificates obtained from formal education than evidence from informal activities that might require some short reflective essay. On the other hand, informal learning is considered by radiographers as a requirement to fulfill lifelong learning activity but one that is not necessarily specific to medical imaging practice.
Simsen et al [35] found a significant relationship among nurses from Hong Kong between marital status and educational level, with married nurses more likely to continue their study and choose generalist courses than single nurses. On the other hand, recent studies [36, 37] found no relationship between marital status and educational qualification in their studies among Australian allied health care professionals and Welsh registered nurses. In this study, no relationship was found between marital status and CPD participation. Is this the result of cultural differences, type of profession, or a direct influence of modern practices? Further study is needed to explain the different findings.

Although marital status did not affect CPD participation, family commitments and shift work negatively influenced CPD participation. This was also noted in other studies among various health professionals [38-40]. Health care organization administrators should take note of this barrier and strive to create a climate in which all health professionals irrespective of their status are able to participate in CPD activities [41, 42].

\section{Motivation for CPD Participation}

Although the motivators for participation in any CPD activity are complex and diverse, there is an agreement among the key stakeholders. Policy makers' motivators are similar to those of professional bodies and to some extent employers. Professionals and policy makers emphasize that health care 
professionals have a duty towards the public to keep their KSC up to date, while management literature suggests that the provision of CPD opportunities encourages the retention of health care professionals [43-45]. The setup of a learning organization, where a group of people are continuously developing their KSC, would lead to competence shifts $[15,16]$ that could either be sustainable as a result of technical innovation or disruptive as a result of some external market pressure that might require a move from one competence to an entirely different new competence. Examples of this competence shift within radiography are imaging interpretation and intravenous therapy resulting from the shortage of radiologists.

Research investigating motivators to CPD participation report that intrinsic motivators such as level of personal motivation, the need to improve professional knowledge and skills, and the desire to increase professional competence were the foremost motivators among the different health care professions [5, 34, 46, 47]. The real benefit of intrinsic motivators over a period of time is sustained participation and transfer to practice. However, intrinsic motivators could prevail over extrinsic motivators such as mandatory $\mathrm{CPD}$ or the possibility of promotion, which may not lead to sustained enthusiasm for CPD or application to practice. It is argued that whenever an external reward is offered for behaviour, the motivation is not bound as tightly to the behaviour. Consequently, forcing adults to undertake learning will not guarantee that learning has indeed contributed to professional and service development [30].

What is interesting in this study is that the results demonstrated that radiographers were generally internally motivated towards CPD. The concept map in Figure 1 indicates that there are a lot more positive concepts towards CPD (grey) than there are negative ones (black). The concept map also features a number of incentives (yellow) that were mentioned by radiographers as likely to improve CPD participation. This augurs well for the Maltese radiography profession and would aid in its endeavours to avoid professional obsolescence where current competence may no longer be sufficient for effective performance [30]. Another motivating factor that featured prominently in the results was "increasing professional competence" highlighting the strong association between the desire for competence enhancement and CPD. However, in this study, the external motivator of obtaining further qualification to apply for promotion was also high. This idea that acquiring a qualification will result in promotion is a misconception that is attributed in part to a strong competition for the few senior posts among a large community of young radiographers all working with the same employer and the lack of other job opportunities in radiography outside the local NHS. This attitude is also fueled by the fact that sectoral trade union agreements promote those who obtain university degrees such as master's degrees to a higher salary scale. This needs to be revisited (renegotiated) because promotion decisions should be dependent on the individual's job-specific and general skills based on continuous skill development and training and not the number of qualifications [48]. This concept merits further investigation.

On the other hand, completing a CPD course without study leave and doing CPD to avoid boredom or to increase self-esteem were the least motivational factors. Doing CPD as a statutory requirement to maintain registration was also not seen as a motivational factor. This was further highlighted with the following comments:

Employer should support CPD during working hours as this enhances the development of the employee and not penalizes her through loss of leave or time in lieu.

I think the employer should at least provide study leave even if unpaid for the CPD courses of the employees.

CPD should not be associated with our registration. Certain radiographers already find it hard to cope as it is so it should not be obligatory. I agree that there should be an incentive, such as promotion; but it shouldn't have anything to do with one's registration. Blackmailing people is not an incentive for CPD!

CPD should not be accompanied by enforced extensive studying. Work/family balance should be maintained. Time off from work should be incorporated in CPD planning otherwise time dedicated to family/leisure will be eroded.

I agree with CPD however if it is compulsory then management have to provide an infrastucture which assists radiographers in achieving $\mathrm{CPD}$ - that means time during working hours in order to undertake CPD activities. Teams have to adapt for this reality while management and HR have to support this good cause. If not resistance to change will push CPD out. More opportunities for everyone in varied CPD activities is also important. CPD can also be part of a performance appraisal programme for radiographers.

Employers should provide funding and study leave to encourage staff to attend CPD activities. However, care should be taken in areas were there are severe shortages of staff.

The above difficulties were the main reasons why participants prefer that CPD participation should not be made mandatory. Therefore, in order to increase participation in the CPD program, some form of support should be available from the employer and professional groups. It was also mentioned that for CPD to be worthwhile there should be a variety of activities that address local needs rather than copying verbatim what is happening abroad. As one participant stated,

I think that overall mandatory CPD is a very good thing if introduced properly. What works in one country doesn't mean that it is going to work in Malta. There should be a wide variety of CPD activities that the individuals can do to maintain registration. This is important as not everyone has the time and money to attend CPD courses. I think that the employers should support all the employees to fulfill 
CPD requirements. Although the government is providing money for CPD activities, I think that there is too much bureaucracy in obtaining this money. It took me 3 years to get the CPD money. Also the money is definitely not sufficient in areas where there is no training available in Malta.

\section{The Meaning of LLL and CPD}

In Ryan's study [5], participants acknowledged that LLL was a combination of general experiences that helped participants to identify their strengths and weakness through reflection. In this study, the open-ended responses clearly showed that radiographers make a clear distinction between LLL as a generic process of ongoing learning and CPD as a specific process for professional development related to radiography. Although radiographers mentioned experiential learning as an opportunity towards LLL, it is apparent that learning through reflection is not included in the radiographers' range of learning methodologies. This is probably the result of not practicing reflective thinking during their undergraduate education or because portfolios for which reflective commentary is a necessary requirement are not yet being used. This may change with the introduction of mandatory CPD, which is expected to be assessed by a portfolio of evidence.

\section{Conclusion and Recommendations}

This study has provided new knowledge for the radiography profession in Malta. The majority of radiographers were self-motivated to engage in CPD activities since CPD provides a method for increasing their knowledge, improves their existing skills, and enhances professional competence. The majority of the participants do not see participation in $\mathrm{CPD}$ as a statutory requirement or an important motivational factor. Formal and structured CPD activities are given much credit and valued more than informal learning. Reflective learning and writing is not practiced. The main constraints experienced by the radiographers were lack of CPD opportunities, funding, and support from management.

It is the opinion of the researchers that radiographers, employers, and the professional groups (Society of Medical Radiographers-Malta and Malta Magnetic Resonance Radiographers Group) should work together to increase opportunities for $\mathrm{CPD}$ as no stakeholder can take sole responsibility for the delivery of a successful CPD program. The authors recommend that if $\mathrm{CPD}$ is to become mandatory, regulations should be laid down making employers share joint responsibility for the setting up of CPD structures within the workplace. Medical imaging departments (through their human resources sections) must strive to enhance learning in the workplace through learning approaches such as experiential learning [49], communities of practice [50, 51], learning organizations [52], and online learning, among others. Encouragement through incentives, such as study leave and protected time to organize lectures during office hours, may increase participation in a mandatory CPD program. The authors query whether the mandatory CPD scheme based on a number of formal learning activities is the best way for such a relatively small group of radiographers who are mostly employed in a single hospital. Instead, the authors suggest a mandatory CPD scheme based on a portfolio of evidence that addresses a set of standards that are relevant to the individual health professional and the medical imaging services in Malta. This would lead to greater flexibility in the content and timing of CPD activities.

\section{References}

[1] Gosling, S. (1999). CPD and competence: related but different: an initial consideration of concepts. Physiotherapy 85, 536-540.

[2] European Commission (2008). The European Qualification Framework for Lifelong Learning (EQF). Luxembourg: Office for Official Publications of the European Communities.

[3] Hardy, M., \& Snaith, B. (2006). Role extension and role advancement-is there a difference? A discussion paper. Radiography 12, 327-331.

[4] Williams, P. L. (1998). Using theories of professional knowledge and reflective practice to influence educational change. Med Teacher 20, $28-34$.

[5] Isop, A. (2013). Continuing Professional Development in Health and Social Care: Strategies for Lifelong Learning. John Wiley \& Sons.

[6] Eraut, M. (1994). Developing professional knowledge and competence. New York: Routledge.

[7] Sadler-Smith, E., Allinson, C., \& Hayes, J. (2000). Learning preferences and cognitive style. Manage Learning 31, 239.

[8] Boyes, C. (2004). Discourse analysis and personal/professional development. Radiography 10, 109-117.

[9] Council for the Professions Complimentary to Medicine. (2006). Code of practice-radiography. Available at: https://ehealth.gov.mt/ HealthPortal/others/regulatory_councils/professions_compl._to_medicine/ professions_compl_to_medicine.aspx. Accessed September 13, 2013.

[10] Edvardsson, B., Meiren, T., Schäfer, A., \& Witell, L. (2013). Having a strategy for new service development-does it really matter? I Service Manage 24, 25-44.

[11] Health Professions Council (2009). Continuing Professional Development and Your Registration. London: Health Professions Council.

[12] Chetcuti, D. (2007). The use of portfolios as a reflective learning tool in initial teacher education: a Maltese case study. Reflective Pract Int Multidisciplinary Perspect 8, 137-149.

[13] Marshall, G., Punys, V., \& Sykes, A. (2008). The continuous professional development (CPD) requirements of radiographers in Europe: an initial survey. Radiography 14, 332-342.

[14] Henwood, S. M., Yielder, J., \& Flinton, D. (2004). Radiographers attitudes to mandatory CPD: a comparative study in the United Kingdom and New Zealand. Radiography 10, 251-258.

[15] Drejer, A., \& Riis, J. O. (1999). Competence development and technology: how learning and technology can be meaningfully integrated. Tech novation 19, 631-644.

[16] Drejer, A. (2001). How can we define and understand competencies and their development? Technovation 21, 135-146.

[17] Novak, J. D., \& Cañas, A. J. (2008). The theory underlying concept maps and how to construct and use them. Florida Institute for Human and Machine Cognition Pensacola Fl. Available at: wwwl.ihmc.us. [http:// cmap.ihmc.us/Publications/ResearchPapers/TheoryCmaps/TheoryUnderlying ConceptMaps.htm]. Accessed September 25, 2013.

[18] Daley, B. J. (2004). Using concept maps in qualitative research. Paper presented at: First International Conference on Concept Mapping. September 14, 2004; Pamplona, Spain. Citeseer.

[19] Novak, J. D., \& Gowin, D. B. (1984). Learning how to learn. Cambridge: Cambridge University Press.

[20] Burgess-Allen, J., \& Owen-Smith, V. (2010). Using mind mapping techniques for rapid qualitative data analysis in public participation processes. Health Expect 13, 406-415. 
[21] Daley, B. J. (2001). Learning and professional practice: a study of four professions. Adult Educ Q 52, 39-54.

[22] CDRT. Centre for Development Research and Training. (2011). Available at: http://cdrt.gov.mt/home?l=1. Accessed January 16, 2011.

[23] Talbot, J., \& Wesrbrook, C. (2011). MRI education. Available at: http:// www.mrieducation.com/courses/index.html. Accessed March 10, 2011.

[24] Baruch, Y. (1999). Response rate in academic studies - a comparative analysis. Hum Relat 52, 421.

[25] Kaplowitz, M. D. (2004). A comparison of web and mail survey response rates. Public Opin Q 68, 94.

[26] Murphy, C., Cross C., \& McGuire, D. The motivation of nurses to participate in continuing professional education in Ireland. J Eur Indust Training 30, 365-384.

[27] Yfantis, A., Tiniakou, I., \& Yfanti, E. (2010). Nurses' attitudes regarding Continuing Professional Development in a district hospital of Greece. Health Sci J 4, 193-200.

[28] Barr, H. (2000). New NHS, new collaboration, new agenda for education. J Interprofess Care 14, 81-86.

[29] Henwood, S., Edie, J., Flinton, D., \& Simson, R. (1998). Continuing professional development-a re-examination of the facts. Radiography 4, 5-8.

[30] Knight, P. (1998). Professional obsolescence and continuing professional development in higher education. Innov Educ Training Int 35, 248-256.

[31] Palarm, T., Jones, K., \& Gilchrist, M. (2001). Personal and professional development: a survey of radiographers employed in the South West Region. Radiography 7, 43-53.

[32] Boud, D., \& Hager, P. (2012). Re-thinking continuing professional development through changing metaphors and location in professional practices. Stud Continuing Educ 34, 17-30.

[33] Salzman, A., \& Hall, K. D. (2013). Human resource development and continuing professional development of physical therapists. Human resource development in the public sector: the case of health and social care, p. 296.

[34] Lee, S., Reed, W., \& Poulos, A. (2010). Continuing professional development: the perceptions of radiographers in New South Wales. Radiographer 57, 33-39.

[35] Simsen, B. J., Holroyd, E., \& Selhck, K. (1996). Postgraduate education expectations: a survey of Hong Kong graduate nurses. J Adv Nurs 24, $827-835$.

[36] Stagnitti, K., Schoo, A., Reid, C., \& Dunbar, J. (2005). Access and attitude of rural allied health professionals to CPD and training. Int J Ther Rehabil 12, 355-362.
[37] Ryan, J. (2003). Continuous professional development along the continuum of lifelong learning. Nurse Educ Today 23, 498-508.

[38] Clifford, R. M., Ram, P. L., \& Lakos, A., et al. (2011). Post-registration learning trends of community pharmacists. J Pharm Pract Res 41, 203.

[39] Moons, K., Evans, S., Lightowlers, M., Bullock, A., \& Barnes, E. (2012). Dental nurses' perception of CPD in Wales. Vital Stat 9, 19-23.

[40] Sykes, H., \& Temple, J. (2012). A systematic review to appraise the evidence relating to the impact and effects of formal continuing professional education on professional practice. J Nurs Educ Pract 2, 194.

[41] Haywood, H., Pain, H., Ryan, S., \& Adams, J. (2012). Engagement with continuing professional development: development of a service model. J Allied Health 41, 83-89.

[42] Brekelmans, G., Poell, R. F., \& van Wijk, K. (2013). Factors influencing continuing professional development: a Delphi study among nursing experts. Eur J Training Dev 37, 313-325.

[43] Eberhard, J., Reinhardt-Mondragon, P., \& Stottlemyer, B. (2000). Strategies for new teacher retention: creating a climate of authentic professional development for teachers with three or less years of experience. ERIC No. ED450116. Corpus Christi, TX: Texas A\&M University.

[44] Probst, H., \& Griffiths, S. (2007). Retaining therapy radiographers: what's so special about us? J Radiother Pract 6, 21-32.

[45] Perkins, A., \& Kron, T. (2007). Continuing professional development needs of Australian Radiation Oncology Medical Physicists - an analysis of applications for CPD funding. Australas Phys Eng Sci Med 30, 226-232.

[46] Gould, D., Drey, N., \& Berridge, E. (2007). Nurses' experiences of continuing professional development. Nurse Educ Today 27, 602-609.

[47] French, H. P., \& Dowds, J. (2008). An overview of continuing professional development in physiotherapy. Physiotherapy 94, 190-197.

[48] Prasad, S., \& Tran, H. (2013). Work practices, incentives for skills, and training. Labour Econ 23, 66-76.

[49] Kolb, D. A. (1984). Experiential learning: experience as the source of learning and development. Englewood Cliffs, NJ: Prentice-Hall.

[50] Wenger, E., McDermott, R., \& Snyder, W. (2002). A guide to managing knowledge. Cultivating communities of practice. Boston, MA: Harvard Business School Press.

[51] Andrew, N., Tolson, D., \& Ferguson, D. (2008). Building on Wenger: communities of practice in nursing. Nurse Educ Today 28, 246-252.

[52] Greenwood, J. (1993). Reflective practice: a critique of the work of Argyris and Schön. J Adv Nurs 18, 1183-1187. 